\title{
Quality of Life in Psoriasis Patients and Its Correlation with Disease Severity
}

\author{
Fakhrozaman Pezeshkpoor1 $^{\text {(D) }, \text { Naghmeh Zabolinejad }}{ }^{* 1}$ (iD Faezeh Golnouri $^{1}$, ShatilaTorabi ${ }^{1}$, Jamile Abed ${ }^{1}$ \\ 1. Cutaneous Leishmaniasis Research Center, Mashhad University of Medical Sciences, Mashhad, Iran
}

\begin{tabular}{|c|c|}
\hline Article Info & ABSTRACT \\
\hline doi $10.30699 / \mathrm{jambs} .26 .119 .1$ & \multirow{4}{*}{$\begin{array}{l}\text { Background \& Objective: Psoriasis is a chronic and relapsing disease with a } \\
\text { prevalence of } 2 \% \text {. Since it is a chronic and non-fatal skin disease, its impact on quality } \\
\text { of life in patients is underestimated compared to other diseases. This study points out } \\
\text { the importance of the quality of life in these patients and their correlation with disease } \\
\text { severity. } \\
\text { Materials \& Methods: Quality of life of psoriasis patients was assessed using the } \\
\text { Dermatology Life Quality Index (DLQI) and psoriasis severity was measured, using } \\
\text { Psoriasis Area Severity Index (PASI). DLQI were compared regarding age, gender and } \\
\text { affected areas in patients. }\end{array}$} \\
\hline $\begin{array}{l}\text { Received: 2018/04/15; } \\
\text { Accepted: 2018/11/17; }\end{array}$ & \\
\hline & \\
\hline $\begin{array}{l}\text { Use your device to scan and read the } \\
\text { article online }\end{array}$ & \\
\hline 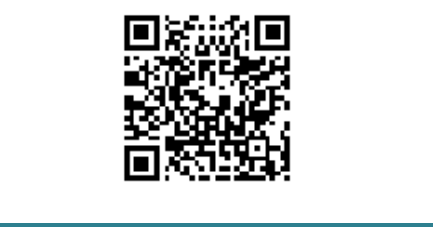 & $\begin{array}{l}\text { Results: Among } 135 \text { patients, } 67(49.6 \%) \text { were male and } 68(50.4 \%) \text { were female. } \\
\text { The mean age of subjects was } 41.49 \pm 15.43 \text { years (ranging from } 17 \text { to } 83 \text { years). The } \\
\text { mean DLQI score was } 10.73 \pm 7.3 \text { (ranging from } 0 \text { to } 26) \text {. Independent t-test showed } \\
\text { that the mean DLQI score was significantly greater in women than men }(P=0.031) \text {. } \\
\text { Spearman test showed positive correlation between DLQI and age as well as PASI } \\
\text { and DLQI. }\end{array}$ \\
\hline $\begin{array}{l}\text { Corresponding Information: } \\
\text { Naghmeh Zabolinejad, Cutaneous } \\
\text { Leishmaniasis Research Center, Mashhad } \\
\text { University of Medical Sciences, Mashhad, } \\
\text { Iran }\end{array}$ & $\begin{array}{l}\text { Conclusion: Results of this study showed a positive and significant correlation } \\
\text { between PASI score and quality of life of patients, which implies that with increasing } \\
\text { the severity of the disease, the effect of psoriasis on patients' quality of life increases } \\
\text { as well. }\end{array}$ \\
\hline Email: zabolinejadng@mums.ac.ir & Keywords: Psoriasis, Quality of life, Dermatology \\
\hline (c) (1) (9) & $\begin{array}{l}\text { cess article distributed under the terms of the Creative Commons Attribution-n } \\
\text { oncommercial usages with proper citation. }\end{array}$ \\
\hline
\end{tabular}

\section{Introduction}

Psoriasis is a chronic relapsing skin disease, characterized by scaly red plaques that are more likely to involve the scalp, knees, and elbows (1). Chronic plaque psoriasis is the most common manifestation of this disease in such a way that almost $80 \%$ of psoriasis cases in adults are of this type $(2,3)$. Psoriasis not only results in physical problems for patients, but also psychological issues and social disabilities (4). It has been shown that the impact of psychological and social problems on psoriasis patients' life is underestimated (5). Psoriasis often makes patients feel embarrassed of their appearance and decreases their self-confidence. Emotional burden due to this disease can affect patients' health and wellbeing (4-6). Many psoriasis patients experience issues like self-esteem problems, poor psychological adjustment, feeling defamed, shame and embarrassment due to their appearance $(6,7)$. Also, it has been found that patients with psoriasis have a significant reduction in the ability to perform physical activities and this reduction is comparable with conditions such as cancer, arthritis, hypertension, ischemic heart disease, diabetes and major depressive disorder (8). It has been shown that $79 \%$ of patients believe that psoriasis had a negative impact on their lives
(9). In addition to the studies mentioned above, studies have been conducted to investigate the quality of life in patients with psoriasis and results indicated a significant impact of the disease on the quality of life in patients with psoriasis $(\mathbf{1 0}, \mathbf{1 1})$. Abedini et al. showed that, psoriasis significantly impairs the quality of life, which is more pronounced in younger patients, women, and patients with a more severe disease (12). In a study by Zandi et al., there was a correlation between the quality of life and disease severity in psoriasis patients (13). It seems that investigating the quality of life in psoriasis patients along with clinical severity of their disease can result in choosing the best type of treatment for these patients. This helps increase the satisfaction level of their treatment. The aim of this study was to evaluate the quality of life of psoriasis patients and its correlation with disease severity in Iran.

\section{Materials and Methods}

\section{Participants}

This cross-sectional study was conducted on 135 patients with chronic plaque psoriasis who referred to Ghaem dermatology clinic in Mashhad during the years 
2013 to 2015. Purposive sampling method was used to collect samples. The ethics committee of Mashhad University approved the study (code: IR. MUMS. REC. 1392.33).

\section{Measurements}

A checklist including demographic data such as age, gender, marital status, and other information like duration of disease was completed by the researcher. To evaluate the quality of life in patients, the Dermatology Life Quality Index (DLQI) was used (14-15). This questionnaire investigated various aspects of a patient's life in dermatology patients, including the patient's symptoms of the skin disease (one question), his/her feelings (one question), patient's daily activities (two questions), his/her Leisure time (two questions), the work or school environment (one question), his/her relationships (two questions), and the treatment of the disease (one question). Patients responded to these questions based on their experiences during the past seven days. Each question had four choices: very much (score 3), a lot (score 2), a little (score 1) and not at all (score 0 ). DLQI score was calculated by adding up the scores of each question. The DLQI score of 0 to 1 meant the disease had no effect on patient's quality of life, the score of 2 to 5 showed a small effect, the score of 6 to 10 revealed a moderate effect, the score of 11 to 20 determined a large effect, and the score of 21 to 30 meant a very large effect on the patient's quality of life (14).

The clinical severity of psoriasis was investigated by Psoriasis Area and Severity Index (PASI). In this method, the whole body was divided into four parts: body ( $10 \%$ of total body surface area), trunk (30\% of total body surface area), upper extremities ( $20 \%$ of total body surface area) and lower extremities (40\% of total body surface area). Within each part, the erythema, induration, itching, and desquamation of the affected areas were scored from 0 to 4 . Also the percentage of skin involvement in each of the four areas was transformed into a grade as follows: 0 ) $0 \%$ of area involved, 1) $1-9 \%$ of area involved, 2) $10-29 \%$ of area involved, 3) 30-49\% of area involved, 4) 50-69\% of area involved, 5) $70-89 \%$ of area involved, and 6) 90 to $100 \%$ of area involved (15).

The validity and reliability of the Persian versions of these questionnaires were investigated and proven in previous studies $(15,16)$.

\section{Statistical Analysis}

The obtained data was analyzed using SPSS 11.5 (SPSS Inc., Chicago, IL., USA). Quantitative Data was reported as mean \pm standard deviation. Independent $\mathrm{T}$ test and Kruskal-Wallis was used to determine statistical differences and the Spearman's test was used to evaluate the correlation between variables. The significance level was considered as P-value $<0.05$ in all tests.

\section{Results}

Among the 135 patients, 67 (49.6\%) cases were male and $68(50.4 \%)$ were female. The mean age of subjects was $41.49 \pm 15.43$ years (ranging from 17 to 83 years). The mean DLQI score was $10.73 \pm 7.3$ (ranging from 0 to 26). The frequency of involved areas in this study was as follows: hands and feet were involved in 17 patients $(12.6 \%)$, extensor areas were involved in 54 patients (40\%), 12 patients had involvement of trunk and the head and neck $(8.9 \%)$, and 52 patients has disseminated psoriasis $(38.5 \%)$. The mean severity score among patients was $5.8 \pm 8.71$ (ranging from 1.0 to 72 ).

Independent t-test showed that the mean DLQI score was significantly greater in women than men $(P=0.031)$. Also Kruskal-Wallis test showed that the mean score of the DLQI in patients with involvement of various areas is significantly different $(P<0.001)$ in a way that the highest mean of DLQI was observed in patients with trunk, head and neck involvement and the lowest mean of DLQI was observed in patients with hands and feet involvement (Table 1).

To compare the mean DLQI score in patients of different ages, patients were divided into age groups of 10 years. As illustrated in Table 2, the frequency of patients was higher in the age group of 41 to 50 years, and the highest mean score of DLQI was observed in the age group of 61 to 70 years. The Kruskal-Wallis test showed that the mean DLQI score in different age groups was significantly different $(P=0.003)$.

Spearman test was used to investigate the correlation between age and DLQI score in patients and the test showed a positive and significant correlation between these two variables $(\mathrm{r}=0.262, P=0.002)$. Similarly, the Spearman test was used to investigate the correlation between PASI score and DLQI score and these variables were also correlated positively and significantly as shown in Table 3 and Figure1 ( $\mathrm{r}=0.617, P<0.001)$.

Table 1. Comparison of the DLQI score in patients with different gender and involved areas

\begin{tabular}{|c|c|c|c|c|c|c|}
\hline & & Frequency & Percentage & DLQI Mean & Standard deviation & P-value \\
\hline \multirow{2}{*}{ Gender } & Male & 67 & 49.6 & 9.41 & 6.79 & \multirow{2}{*}{$=0.031$} \\
\hline & Female & 68 & 50.4 & 12.03 & 7.08 & \\
\hline \multirow{4}{*}{$\begin{array}{c}\text { Involved } \\
\text { area }\end{array}$} & Hands and feet & 17 & 12.6 & 7.88 & 3.82 & \multirow{4}{*}{$<0.001$} \\
\hline & Extensor areas & 54 & 40.0 & 8.07 & 6.60 & \\
\hline & Trunk and head and neck & 12 & 8.9 & 14.33 & 9.21 & \\
\hline & Disseminated & 52 & 38.5 & 13.59 & 6.34 & \\
\hline
\end{tabular}



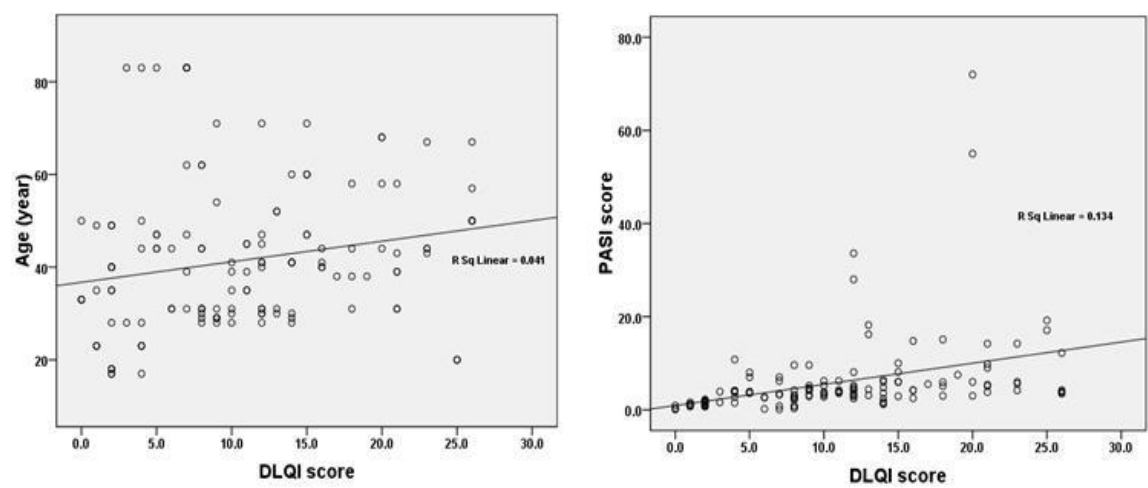

Figure 1. Correlation between variables in study and DLQI Score

Table 2. Comparison of the DLQI score in patients with different age groups

\begin{tabular}{ccccc} 
Age & $\begin{array}{c}\text { Frequency of } \\
\text { Patients }\end{array}$ & Mean DLQI Score & Standard Deviation & P-value \\
$\mathbf{0 - 2 0}$ & 8 & 8.00 & 10.52 \\
$\mathbf{2 1 - 3 0}$ & 26 & 7.85 & 4.31 \\
$\mathbf{3 1 - 4 0}$ & 37 & 10.00 & 6.67 & $=0.003$ \\
$\mathbf{4 1 - 5 0}$ & 38 & 12.26 & 7.50 & \\
$\mathbf{5 1 - 6 0}$ & 10 & 16.40 & 4.90 & 8.06 \\
61-70 & 7 & 16.00 & 3.84 \\
\hline 70 and older & 9 & 7.67 & & \\
\hline
\end{tabular}

Table 3. Correlation between variables in study and DLQI Score

\begin{tabular}{c|cc}
\hline Variables & $\mathbf{R}$ & P-value \\
Age & $=0.262$ & $=0.002$ \\
PASI score & $=0.617$ & $<0.001$ \\
\hline
\end{tabular}

\section{Discussion}

Psoriasis is a chronic and relapsing disease that does not have a definite and proven treatment. It can have a significant impact on patients' physical and mental health. Previous studies have shown that psoriasis has greater effect on the mental health and quality of life of patients than any other chronic diseases such as cancer, hypertension, myocardial infarction, arthritis, type 2diabetes and major depressive disorder (8). So far, several studies have reviewed the factors affecting the quality of life in psoriasis patients; however, these studies did not have identical results.

In the present study, the comparison of the DLQI score in patients with different gender showed that this disease has a greater effect on women's quality of life. Most of the previous studies also indicated that the effect of this disease on quality of life is greater in women. Gelfand et al., Sampogna et al., as well as Mabuchi et al. have reported this subject in the same way in their studies (1719). To explain this finding, it can be stated that women care more about their appearance and are more dependent on social relationships. Thus, a chronic disease like psoriasis that affects the appearance of patients can reduce the quality of life in women more than men.

In addition, this study shows that the chronic plaque psoriasis of trunk, head, and neck and the disseminated form of chronic plaque psoriasis have a greater effect on patients' quality of life in comparison with chronic plaque psoriasis of hands and feet and extensor areas. The chronic plaque psoriasis of trunk, head and neck and disseminated form of chronic plaque psoriasis are the more exposed to public view, so their lesions have further impact on patients' beauty and self-esteem. As a result, in case of psoriasis in these areas, we expect a greater effect on patients' quality of life.

Also, this study shows that by increasing age, the effect of psoriasis on patients' quality of life increases, where a positive correlation was observed between age and DLQI score. Studies have reported different results about the impact of psoriasis on quality of life in patients 
with different ages. Lin et al. and Lundberg et al. showed that the effect of psoriasis on patients' quality of life was greater in young people $(\mathbf{2 0}, \mathbf{2 1})$. On the other hand, in the present study as well as the study by Samponga et $a l$. , it was observed that the impact of psoriasis on quality of life in older patients was greater (19). This difference might be the result of cultural differences in different countries (20). In a systematic review by Mattei et al., mean PASI and DLQI correlated predictably in patients with chronic moderate-to-severe plaque psoriasis under treatment with biological agents (22).

In a study by Rencz et al. in 2018 in Hungry, a high rate of 'non-relevant' response (NRR) on DLQI of psoriasis was demonstrated in patients especially among less educated and elderly women (22). As a result, reconsidering the usage of the DLQI for medical and financial decision-making in psoriasis patients was suggested (23). Another study by Rencz et al. pubished in 2018 proposed a new scoring formula, DLQI-R that adjusts the total score to the number of NRRs (24). Further studies are needed to investigate this issue.

\section{Conclusion}

The results of this study showed a positive and significant correlation between PASI score and quality of life of patients with psoriasis in Iran. As the severity of the disease increases, the effect of psoriasis on patients' quality of life increases too.

\section{Acknowledgements}

The authors would like to thank Ms. Akram Momenzadeh for her valuable assistance in preparing and submitting this manuscript. This project was supported by a grant from the Vice Chancellor for Research of Mashhad University of Medical Sciences for a proposal (Dr Jamileh Abed) with approval number 910993.

\section{Conflict of Interest}

Authors declare no conflict of interests with respect to the present paper.

\section{References}

1. Böhm D, Stock Gissendanner S, Bangemann K, et al. Perceived relationships between severity of psoriasis symptoms, gender, stigmatization and quality of life. J Eur Acad Dermatol Venereol. 2013; 27(2): 220-6. [DOI:10.1111/j.1468-3083.2012.04451.x] [PMID]

2. Schöffski O, Augustin M, Prinz J, et al. Costs and quality of life in patients with moderate to severe plaque-type psoriasis in Germany: A multi-center study. J Dtsch Dermatol Ges. 2007; 5(3): 209-18 [DOI:10.1111/j.16100387.2007.06240.x] [PMID]
3. Feldman S, Pearce D. Epidemiology, clinical manifestations, and diagnosis of psoriasis. UpToDate, Waltham. 2013.

4. De Korte J, Mombers FM, Bos JD, Sprangers MA. Quality of life in patients with psoriasis: a systematic literature review. J Invest Dermatol Symposium Proceedings. 2004: 9(2): 140-7. [DOI:10.1046/j.1087-0024.2003.09110.x] [PMID]

5. Choi J, Koo JY. Quality of life issues in psoriasis. J Am Acad Dermatol. 2003; 49(2): 57-61. [DOI:10.1016/S01909622(03)01136-8]

6. Mease PJ, Menter MA. Quality-of-life issues in psoriasis and psoriatic arthritis: outcome measures and therapies from a dermatological perspective. J Am Acad Dermatol. 2006; 54(5): 685-704. [DOI:10.1016/j.jaad.2005.10.008] [PMID]

7. Bhosle MJ, Kulkarni A, Feldman SR, Balkrishnan R. Quality of life in patients with psoriasis. Health Qual Life Outcomes. 2006; 4: 35. [DOI:10.1186/1477-7525-4-35] [PMID] [PMCID]

8. Rapp SR, Feldman SR, Exum ML, et al. Psoriasis causes as much disability as other major medical diseases. J Am Acad Dermatol. 1999; 41: 401-7. [DOI:10.1016/S01909622(99)70112-X]

9. Krueger G, Koo J, Lebwohl M, et al. The impact of psoriasis on quality of life: results of a 1998 National Psoriasis Foundation patient-membership survey. Arch Dermatol. 2001; 137(3): 280-4.

10. Martínez-García E, Arias-Santiago S, Valenzuela-Salas I, et al. Quality of life in persons living with psoriasis patients. J Am Acad Dermatol. 2014; 71(2): 302-7. [DOI:10.1016/j.jaad.2014.03.039] [PMID]

11. Aghaei S, Moradi A, Ardekani GS. Impact of psoriasis on quality of life in Iran. Indian J Dermatol Venereol Leprol. 2009; 75(2): 220. [DOI:10.4103/0378-6323.48689] [PMID]

12. Abedini R, Lajevardi V, Hallaji Z, Khodashenas Z, Zafar F, Nasimi M. Quality of life in patients with psoriasis: A crosssectional study in a dermatology referral hospital in Tehran, Iran. Iran J Dermatol. 2016; 19(4): 113-18.

13. Zandi S, Shamsi S, Hashemi S, Saburi F. Evaluation of quality of life in patients with psoriasis. J Dermatol and Cosmetetic. 2011; 2(3): 166-73.

14. Finlay AY, Khan G. Dermatology Life Quality Index (DLQI)-a simple practical measure for routine clinical use. Clin Experiment dermatol. 1994; 19(3): 210-6. [DOI:10.1111/j.1365-2230.1994.tb01167.x]

15. Feldman SR, Fleischer AB, Reboussin DM, et al. The selfadministered psoriasis area and severity index is valid and reliable. J Invest Dermatol. 1996; 106(1): 183-6. [DOI:10.1111/1523-1747.ep12329912] [PMID]

16. Aghaei $\mathrm{S}$, Sodaifi $\mathrm{M}$, Jafari $\mathrm{P}$, et al. DLQI scores in vitiligo: reliability and validity of the Persian version. BMC Dermatol. 2004; 4: 8. [DOI:10.1186/1471-5945-4-8] [PMID] [PMCID]

17. Mabuchi T, Yamaoka H, Kojima T, et al. Psoriasis affects patient's quality of life more seriously in female than in male in Japan. Tokai J Exp Clin Med. 2012; 37(3): 84-8. [PMID]

18. Gelfand JM, Feldman SR, Stern RS, et al. Determinants of quality of life in patients with psoriasis: a study from the US 
population. J Am Acad Dermatol. 2004; 51(5): 704-8. [DOI:10.1016/j.jaad.2004.04.014] [PMID]

19. Sampogna F, Chren M, Melchi C, et al. Age, gender, quality of life and psychological distress in patients hospitalized with psoriasis. $\mathrm{Br} \mathrm{J}$ Dermatol. 2006; 154(2): 325-31. [DOI:10.1111/j.1365-2133.2005.06909.x] [PMID]

20. Lin TY, See LC, Shen YM, et al. Quality of life in patients with psoriasis in northern Taiwan. Chang Gung Med J. 2011; 34(2): 186-96. [PMID]

21. Lundberg L, Johannesson M, Silverdahl M, et al. Healthrelated quality of life in patients with psoriasis and atopic dermatitis measured with SF-36, DLQI and a subjective measure of disease activity. Acta DermatovenereologicaStockholm. $\quad 2000 ; \quad 80(6)$ : $430-4$ [DOI:10.1080/000155500300012873] [PMID]
22. Mattei PL, Corey K, Kimball A. Psoriasis Area Severity Index (PASI) and the Dermatology Life Quality Index (DLQI): the correlation between disease severity and psychological burden in patients treated with biological therapies. J Eur Acad Dermatol Venereol. 2014; 28(3): 3337. [DOI:10.1111/jdv.12106] [PMID]

23. Rencz F, Poór AK, Péntek M. A detailed analysis of 'not relevant' responses on the DLQI in psoriasis: potential biases in treatment decisions. J Eur Acad Dermatol Venereol. 2018; 32(5): $\quad 783-90 . \quad$ doi: $\quad 10.1111 / j d v .14676$ [DOI:10.1111/jdv.14676] [PMID]

24. Rencz F, Gulácsi L, Péntek M. Proposal of a new scoring formula for the DLQI in psoriasis. Br J Dermatol. 2018; 179(5): $\quad 1102-108 . \quad$ https://doi.org/10.1111/bjd.16927 [DOI:10.1111/bjd.17214] [PMID].

\section{How to Cite This Article:}

Pezeshkpoor F, Zabolinejad N, Golnouri F, Torabi S, Abed J. Quality of Life in Psoriasis Patients and Its Correlation with Disease Severity. J Adv Med Biomed Res. 2018; 26 (119) :1-5

\section{Download citation:}

$\underline{\text { BibTeX }}|\underline{\text { RIS }}| \underline{\text { EndNote }}|\underline{\text { Medlars }}| \underline{\text { ProCite }}|\underline{\text { Reference Manager }}| \underline{\text { RefWorks }}$

\section{Send citation to:}

Mendeley 2 Zotero (i) RefWorks RefWorks 